\title{
NOG EENS EMIGRATIE VAN NEDERLANDERS
} NAAR SURINAME

\author{
DOOR
}

W. R. MENKMAN

In het Algemeen Handelsblad van 24 en 25 Februari d. j. leverde Dr. Th. J. Lens een pleidooi voor emigratie van Nederlanders naar Suriname, waarin hij wilde aantoonen dat, mits dit land geassaineerd wordt, kolonisatie van Europeanen evengoed mogelijk is als van Aziaten. Of de kolonisatie van Europeanen, speciaal Nederlandsche landbouwers, in Suriname gewenscht is zou volgens Dr. L. geen open vraag meer zijn; door verruimd wetenschappelijk inzicht en door een proefneming op groote schaal zou sedert het in 1896 verschenen rapport der Staatscommissie van 1892 deze vraag (in bevestigenden zin) beantwoord zijn.

Had Dr. L. er zich toe bepaald de mogelijkheid eener kolonisatie als de bedoelde uit medisch oogpunt te belichten, aan de hand van de meer recente assaineeringsgeschiedenis van tropische landen, dan zou ik de laatste zijn geweest om zich bevoegd of geroepen te voelen tegen zoodanige voorlichting eenige bedenking in het midden te brengen. De geachte schrijver evenwel gaf een pleitrede voor een emigratie ,en masse" van Nederlandsche landbouw-arbeiders naar Suriname, waarmede zonder talmen een aanvang zou moeten worden gemaakt, met het doel om binnen een menschen-leeftijd het Surinaamsche bevolkings-vraagstuk tot oplossing te brengen - en tevens het gevaar eener overbevolking in het Noederland te bezweren - en hij maakte daarbij vergelijkingen en haalde voorbeelden aan, welke aan dit pleidooi steun zouden moeten verleenen. Althans zóó heb ik het artikel 
in kwestie gelezen en zóó zullen ook anderen het hebben gelezen; ik geloof door deze bewering aan de intelligentie van den gemiddelden Handelsblad-lezer geen onrecht aan te doen.

Mij leken die vergelijkingen en die voorbeelden niet altijd geheel juist en ter zake dienende en ik heb daarvan blijk gegeven in een artikel van Maart d. j., dat echter eerst in de Juni-aflevering van dit tijdschrift werd opgenomen. Wellicht had ik mijn vragen en opmerkingen naar aanleiding van Dr. L.'s Februari-artikel achterwege gelaten wanneer ik eerder had kunnen kennisnemen van hetgeen het Surinaamsche blad De West onder den titel „Een wonderlijk plan” ter zake in het midden heeft gebracht.

Dr. Lens dient mij van antwoord in het Juli/Augustusnummer van den W. I. Gids; hij doet dit, volgens eigen erkentenis, op scherpen toon, waar ik geen bezwaar tegen zou hebben indien de geachte schrijver zich van „personal verdicts" had weten te onthouden.

In de eerste plaats had mij getroffen de door Dr. L. gemaakte vergelijking tusschen de schaarsche en slappe bevolking van het ongezonde Suriname aan den eenen kant en het overbevolkt geraken, van blanken zoowel als van negers, van het droge en onbeboschte Curaçao anderzijds. Ik maakte hierbij de opmerking dat het verschil in bevolkings-dichtheid niet uitsluitend mag worden verklaard uit het meer of minder ,gezonde" van het land. Het gaat hier immers over twee kunstmatig bevolkte gewesten en ik meende het verschil op de kortste wijze te kunnen typeeren door de tegenstelling plantageland-slavendepôt. Waar Curaçao langen tijd het centrum was van den Westindischen slavenhandel, waar negers werden aangevoerd als veel winst-gevende handelswaar voor wederuitvoer naar de Spaansche koloniën en waar het blijvende contingent vergelijkenderwijs mild werd behandeld ${ }^{1}$ ), kreeg Suriname slechts zooveel zwarte werkkrachten als voor

1) In Curaçao bestond in 1850 de bevolking voor ruim $50 \%$ uit vrijen, in 1863 voor ruim $68 \%$; in Suriname waren de cijfers respectievelijk ruim $34 \%$ en ruim $44 \%$. 
het inheemsche plantage-bedrijf in het kleine ontgonnen gedeelte noodig waren, en vaak zelfs minder dan men verlangde, terwijl later de aanvoer van Aziatische koelies natuurlijk regelrecht verband hield met de meerdere of mindere welvarendheid van den grooten landbouw.

In Suriname zagen de plantage-houders niet altijd het belang in der natuurlijke vermeerdering van de slaven en de plantage-toestanden waren ook niet bevorderlijk aan zoodanige vermeerdering ${ }^{1}$ ). Klachten over een te geringen aanvoer van vrouwen kwamen in den slaventijd ook voor.

En wat de overbevolktheid van Curaçao aangaat, daarvan is thans niet veel meer te bespeuren, nu op het hoofdeiland industrie en scheepvaart zich zoozeer hebben ontwikkeld. Wel is dit proces er een van den allerlaatsten tijd, maar: „aanzienlijk”, zegt de Encyclopaedie van Nederlandsch West Indië (1914/1917) onder het hoofd Curaçao „kan men den aanwas der bevolking niet noemen, want hij bedroeg gedurende de laatste halve eeuw niet veel meer dan $1 \%$ per jaar."

Van 53702 zielen op het einde van 1920 vermeerderde de Curaçaosche bevolking door geboorteoverschot tot einde 1925 met 3790 zielen, of $70.6 \%$. Dezelfde berekening makende voor Nederland komt men voor dezelfde periode op $78.9 \%$.

Dr. Lens stelt mij de vraag of ik denk dat er op Curaçao nooit „intensen landbouw gedreven is" en spreekt van een cochenille- en aloëcultuur, van handel in oranjeschillen en divi-divi. De geachte schrijver had o. a. ook nog kunnen releveeren de in 1688 gestaakte suiker-cultuur op de Compagnie's-plantages, maar desniettemin zijn op Curaçao nooit groote cultures ontstaan en in stand gebleven als in Suriname. Het begrip plantage is op Curaçao iets anders dan in Suriname en ook voordat Curaçao verindustrialiseerd was, waardoor thans in de buiten-districten zoo weinig werkvolk is te vinden, moes-

1) Terwijl in Suriname bij de slaven het sterfte-cijfer voortdurend het geboorte-cijfer overtrof wisten de vrije boschnegers zich te handhaven, ook toen hun aantal niet meer toenam door nieuwe wegloopers. 
ten de Curaçaosche plantage-houders maar al te vaak hun rekening trachten te maken door verkoop van putwater, brandhout, houtskool, steenen, kalk, zout, hoewel natuurlijk, zooals algemeen bekend is, het eiland ook oranjeschillen en aloë oplevert en er vele geiten en een weinig rundvee (voor melk-voorziening) wordt gehouden; divi-divi is niet bepaald een landbouwproduct.

De aanvankelijk voor mij minder begrijpelijke overbevolktheid van Curaçao wordt thans door Dr. L. toegelicht door te verwijzen naar de emigratie van zwarte en blanke Curaçaoenaars en naar de ongunstige betalingsbalans van 1913. De - zacht uitgedrukt - sterk overdreven voorstelling van zaken als zou, dank zij den $\mathrm{Cu}-$ raçaoschen arbeider-emigrant, het Papiamentsch in de kustplaatsen van Venezuela inheemsch zijn nu maar ter zijde latende moet thans de bedoeling van den schrijver duidelijk worden geacht. Maar, deze soort overbevolktheid laat zich ook met betrekking tot Suriname aantoonen.

Ook Surinamers, handwerkslieden en intellectueelen, zochten en vonden bij de vleet een goed of een beter heenkomen buiten hun geboorteland, naar Holland, OostIndië, Curaçao, de Vereenigde Staten, en wat de verhouding tusschen invoer en uitvoer betreft is het heel natuurlijk dat Curaçao met zijn scheepvaartstation en bunkerhaven reeds in 1913 in een bizondere positie verkeerde $^{1}$ ).

Een tweede bedenking welke bij mij gerezen was tegen het pleidooi van Dr. L. - en ik zag later dat De West dezelfde bedenking heeft geopperd - had betrekking op het door den geachten schrijver medegedeelde uit de geschiedenis der doorgraving van de Landengte van Panama, dat het bewijs zou opleveren voor de stelling dat ook blanken in de tropen zwaar grond- en handwerk kunnen verrichten, mits de hygiënische voorwaarden goed zijn. Niet dat ik twijfelde aan de geschiktheid van blanken tot lichamelijken arbeid in de tropen, in bepaalde

${ }^{1}$ ) Tegenwoordig is van de bevolking van het eiland Curaçao niet minder dan $45 \%$ ter hoofdplaats gevestigd. 
omstandigheden en onder bepaalde voorwaarden, maar ik had bij herhaalde bezoeken aan de Landengte, vóór en nadat het Kanaal geopend was, nimmer den indruk gekregen dat wat de Amerikanen aldaar te aanschouwen gaven kon worden aangemerkt als een geslaagde proefneming van kolonisatie van blanken in de heete luchtstreek; ook lag het m. i. voor de hand dat niet alle blanken bij den kanaal-aanleg handen-arbeid hebben verricht. Ik stelde daarom eenige vragen en sprak over de Jamaica-negers en andere gekleurden, die dan toch ook in 1911, het jaar waarover Dr. L. het had, sterk in de meerderheid waren. De geachte schrijver heeft in Goethals' werk „The Panama Canal” het antwoord op mijn vragen niet kunnen vinden, maar wel dat de gekleurde arbeiders meest negers van Barbados en de Fransche eilanden waren en de ongeschoolde Europeanen meest Spanjaarden. Goed, maar wanneer men daarbij bedenkt dat in het contingent blanken ook begrepen waren de Amerikaansche staf en de geschoolde vaklieden, dan is men wel geneigd om zich te scharen aan de zijde van de schrijvers die beweerd hebben dat, met alle respect voor de prestaties der Amerikaansche Genie, van den Amerikaanschen Geneesk. dienst en van de "gold employees", het toch, wat de eigenlijke „main d'oeuvre” betreft, de Westindische neger is geweest die de doorgraving mogelijk heeft gemaakt.

Dr. Gorgas, de zoo verdienstelijke leider van het assaineerings-werk op de Landengte, moge een enthousiast voorstander zijn geweest der kolonisatie van blanken in de tropen, dat neemt toch niet weg dat het bestuur der Canal Zone nog maar weinige jaren geleden strenge maatregelen nam tegen de toelating van blanken, natuurlijk om tegen te gaan dien allertreurigsten uitwas van alle kolonisatie in heete landen, werkeloosheid en pauperisme onder de blanke bevolking.

Het is steeds de bedoeling geweest kanaal-werkers die niet meer noodig waren zoo snel mogelijk te laten afvloeien; „settlers were not wanted”.

In 1910 waren er bij de Isthmian Canal Commission en 
de Panama Railroad Company tezamen ruim 38.000 menschen in dienst, waarvan rum 30.000 bij eerstgenoemde.

De zoogenaamde „silver-force” (ongeschoolde werkkrachten) bestond uit ongeveer 5000 Europeanen (ZuidEuropeanen met lagen levensstandaard) en ongeveer 28.000 Westindische negers.

De nagenoeg geheel uit Amerikanen bestaande „goldforce" omvatte de staf, de administratieve employés, de constructie-werklieden en de andere geschoolde ambachtslieden, tezamen ongeveer 5000 personen.

In tegenstelling met de intellectueele werkkrachten, die schriel betaald werden, waren de handwerkslieden die tot de ,gold force” behoorden de best betaalde arbeiders der wereld. Scheepswerf-arbeiders, machinisten, metaal-bewerkers, ketelmakers, timmerlieden, bedienings-manschappen voor de excavateurs, huizenbouw-arbeiders etc. verdienden nominaal evenwel als in de V. S., maar inderdaad was hun loon belangrijk hooger, in aanmerking genomen vrije woning, goedkoope voedingsmiddelen, door de Commissary Departement verstrekt, etc.

Van de kolonisatie van Suriname door Javanen sprekende zeide Dr. Lens in zijn Handelsblad-artikel „onge„twijfeld zal zulk een kolonisatie slagen, mits de gezond„heidsdienst in Suriname op Amerikaansche leest ge„schoeid worde, naar het voorbeeld van dien te Panama „en Cuba, die ook tropenlanden zijn met blanke arbei"ders, en de Zuidelijke Staten van N. Amerika."

Dat de Amerikanen veel succes hebben gehad bij de bestrijding van de gele koorts, niet alleen op de Landengte van Panama, maar ook in Havana en in sommige van hun eigen Zuidelijke havens was mij bekend; ik heb het echter wenschelijk geacht te waarschuwen tegen den indruk als zouden ook Cuba en de Zuidelijke Staten der Unie goede voorbeelden zijn van tropenlanden met blanke arbeiders, natuurlijk in verband met het pleidooi voor kolonisatie van Hollanders in Suriname.

Wat Cuba betreft dacht ik aan de arbeiders uit Zuidelijk Europa die althans in vroeger jaren geregeld met de 
van Italië en Spanje varende stoomvaartlijnen naar het eiland overkwamen, om na afloop van het seizoen weder naar huis terug te keeren. Ook stond mij voor den geest het rapport van den Vice-consul Dr. E. Bunge „Cuba beschouwd met het oog op de belangen van Nederland" (Consulaire Verslagen 6e jaargang) waarin werd aangehaald een uitspraak van Dr. P. Karntz, Industrial Agent of the Cuban R. R. Co., welke laatste aan landbouwers ontraadde om naar Cuba te komen wanneer niet in het bezit van 10 à $12 \frac{1}{2}$ duizend gulden (dat was vóór den oorlog); Dr. Bunge zelf voegde hieraan toe dat er z.i. voor Nederlanders niet veel anders zou overblijven dan hetzij tuinbouwer te worden dicht bij Havana of een andere groote stad, of wel in de buurt van Camagüey of misschien Manzanillo rundvee te koopen en boter en kaas te gaan maken. Blanke kolonisten zouden derhalve op Cuba alleen kans hebben als kleine plantage-houders of veeboeren.

$\mathrm{Nu}$ komt Dr. Lens mij vertellen dat $\frac{2}{3}$ der Cubaansche bevolking uit blanken bestaat, dat Havana een schoone en volkrijke stad is en dat sedert eeuwen op Cuba blanken den akkerbouw beoefenen; de geachte schrijver vraagt of ik werkelijk meen dat blanken op Cuba geen zwaren physieken arbeid verrichten. In Havana heb ik wel eens enkele dagen vertoefd, met Cuba heb ik nogal eens relaties gehad en, hoewel gedurende mijn Westindischen tijd Paramaribo en Curaçao mijn standplaatsen waren, heb ik door mijn beroep de laatste 20 à 25 jaren volop gelegenheid gehad om algemeene Westindische noties te verkrijgen.

Zoo weet ik dat ook in de Latijnsche landen der Nieuwe Wereld de standskwestie nauw verband houdt met de ras- en kleurkwestie, dat een breede klasse van „criollos” gaarne voor blank doorgaat, ook al is de raszuiverheid dubieus, en dat ook wel statistisch als zoodanig wordt aangemerkt alles wat noch Indiaan, noch Neger, noch Mulat is; in Porto Rico geldt in de bevolkings-statistiek wel drie vierde der bevolking als blank. Op Cuba vond Columbus een Indiaansche bevolking van misschien een miljoen zielen, welke wel niet zal zijn uitgestorven of uit- 
geroeid zonder dat van haar bloed een deel in dat van de nieuwkomers was overgegaan; de Spanjaarden, die partij wilden trekken van de vruchtbaarheid des bodems, maar voor zich zelf plantagewerk te zwaar vonden, begonnen ook hier al spoedig negerslaven uit Afrika in te voeren.

De meeningen loopen uiteen over de vraag of en hoeveel Indianen-bloed er nog in de tegenwoordige Cubaansche bevolking is overgebleven. Dat de eigenlijke Cubanen van tegenwoordig in groote meerderheid „negroid” zijn schijnt evenwel niet voor tegenspraak vatbaar, hoewel velen voor blank doorgaan. Waar reeds zeer vroeg in de $16 \mathrm{e}$ eeuw een aanvang is gemaakt met den invoer van Afrikaansche slaven ligt dit ook voor de hand.

Of de Cubaansche creolen, die niet behooren tot de categorie van negers en mulatten, geen zwaren lichamelijken arbeid verrichten? Allicht wel; er worden in een land als Cuba vele bedrijven en beroepen uitgeoefend, waaronder echter ook minder inspanning eischende als dat van sigarenmaken, om maar een enkel voorbeeld te noemen. Voor de groote cultures echter hebben de oude meesters van het land negers noodig gehad uit Afrika en ook in onzen tijd zijn er negers heengetrokken uit Jamaica, en ook uit Curaçao, hoewel de Amerikaansche suikerplantages zoodanig zijn geoutilleerd dat met een minimum van handen-arbeid kan worden volstaan; toen de boom-periode voorbij was heeft de Britsche Regeering diplomatieke stappen moeten doen en heeft het Curaçaosche Gouvernement schepen moeten zenden om de menschen terug te halen, wegens de vele klachten welke uit Cuba werden vernomen over mishandeling en armoede.

Inderdaad, ook al hebben de Amerikanen de havenstad Havana practisch vrij gemaakt van gele koorts, toch is het beter aan Cuba niet te denken wanneer men zoekt naar voorbeelden van tropische landen waar de ontginning van den bodem en de landbouw op groote schaal door den handenarbeid van Europeesche kolonisten is tot stand gebracht, hoewel dit eiland, wat ligging, klimaat en bodemgesteldheid betreft, zich beter dan Suriname voor Europeesche kolonisatie zou hebben geleend. 
Merkwaardig is het eerder dat Cuba, een der Westindische eilanden waar de Europeanen het eerst vasten voet kregen, zooveel minder dicht bevolkt is geraakt dan Jamaica en Trinidad, om van Barbados niet eens te spreken.

In het algemeen zal men in West-Indië weinig vinden dat steun geeft aan de stelling dat onder gunstige omstandigheden kolonisatie van Nederlandsche landbouwers in Suriname zeker zou slagen, en daarom toch gaat het. De geschiedenis van mislukte kolonisaties moge niet voldoende argumenten opleveren tegen die stelling, de geschiedenis der bevolking, of der herbevolking, van de nieuwe wereld in het algemeen is te gecompliceerd, ook met betrekking tot het blanke element, om houvast te geven aan de propagandisten. Spanje, en ook Engeland, hebben in vroegere eeuwen zelfs door de deportatie van misdadigers en vagebonden het allegaartje van rassen en kleuren in de West-Indiën helpen tot stand brengen.

Te wijzen op de door de Amerikanen bereikte resultaten bij de bestrijding der gele koorts en andere tropenziekten in enkele havensteden der Caraibische Zee en der Golf van Mexico, alsmede op de Landengte van Panama, heeft evenveel, of even weinig waarde voor het vraagstuk eener Nederlandsche emigratie naar Suriname als de aandacht te vestigen op de ,jibaros" en de „poor whites” op sommige Westindische eilanden als afschrikwekkende voorbeelden.

En wat de Zuidelijke Staten der Unie betreft, gelegen buiten de tropen, wie uit West-Indië komende die staten doorreist blijft zich omringd zien van negers, in het openbaar overal angstvallig afgescheiden gehouden van het blanke deel der bevolking. Dat de Federale Regeering ,farming” in de Zuidelijke Staten door blanken aanmoedigt is goed en wel, maar daarbij zal wel niet de bedoeling voorzitten om den neger in de katoen-velden door den blanke te vervangen, nu eerstgenoemde de neiging is gaan vertoonen om Noordwaarts te trekken, naar de centra met hoogen loonstandaard. Onder „farming” wordt in Amerika ook verstaan wat in Suriname plantagebedrijf zou heeten (vruchten-cultuur, etc.). 
Voordat, onder den invloed van den oorlog en van de immigratie-wetten, de negers begonnen te verhuizen naar de Staten met hoogen loonstandaard, werd het grootste deel der producten van de Zuidelijke Staten door hun arbeid verkregen en bijna een zesde van alle land-arbeid in de Unie werd door hen verricht. Gedurende 40 jaren van vrijheid was de neger-bevolking der V. S. van $4 \frac{1}{2}$ miljoen tot 9 miljoen toegenomen.

De groote uittocht naar de streken met hoogere loonen bracht een revolutie teweeg in de landbouw-toestanden van die staten waar voorheen de negers het talrijkste waren geweest, vooral in de zoogenaamde „cotton belt"; arbeidsloonen stegen enorm en landprijzen daalden onrustbarend.

Alle krachten moesten worden ingespannen om door betere landbouwmethoden compensatie te'verkrijgen voor het verlies van overvloedigen en goedkoopen arbeid en van de hulp en de voorlichting der Regeering hebben de gekleurde "farmers" der Zuidelijke Staten niet minder partij weten te trekken dan de blanke.

Dat blanken in de tropen physieken arbeid kunnen verrichten, zelfs zwaren lichamelijken arbeid, zal niemand ontkennen, vooral niet hij die lang onder de keerkringszon heeft geleefd; ik heb zelf een voorbeeld aangehaald uit Curaçao. Alleen was het mij niet duidelijk welke gevallen Dr. Lens uit eigen Curaçaosche ervaring voor den geest stonden, waar hij den Hollandschen werkman aldaar niet kan hebben waargenomen. Thans blijkt dat de geachte schrijver in zijn tijd wel eens blanke Curaçaoenaars buiten op het veld heeft zien medewerken en in de stad in de winkels heeft bezig gezien, militairen aan sport heeft zien doen, zelf gewoon was een deel zijner practijk te paard af te doen etc. Mijn nieuwsgierigheid is nu bevredigd, maar mijn bezwaar blijft bestaan, wat de strekking betreft, tegen de zinsnede: „vooral op Curaçao, waar tropenziek„ten niet voorkomen, was ik daarvan getuige.”

Ook elders tusschen de keerkringen, waar tropenziekten wèl voorkomen, zijn zelfs geboren Europeanen tot zwaren lichamelijken arbeid in staat gebleken, wanneer 
de omstandigheden dat zoo eens meebrachten. Behalve de voorbeelden welke Dr. L. daarvan zelf aanhaalde uit de geschiedenis van Suriname kan o.a. nog gewezen worden op den handen-arbeid welke ook aldaar door Europeesche militairen werd verricht en aan sport deden zij er in mijn tijd eveneens. Een oud-officier hoorde ik eens vertellen hoe men vroeger te Harderwijk aan de voor Suriname gemonsterden den spotnaam van houthakkers gaf, vanwege de soort arbeid welke van hen zou worden verlangd.

Om der wille van de propaganda moge men het er wat dik bovenop leggen, in de verwachting dat de wel geinformeerde lezer veel zal opvatten „cum grano salis”, maar daarmede doet men niet altijd goed; men riskeert daarmede misverstaan te worden of zich voor consequenties te zien gesteld welke men niet heeft gewenscht.

Dr. Lens vertoonde zelfs het spook van een „finis coloniae"; tegelijk met de kreet „Java voor de Javanen" zal z. i. in het Westen die van "Suriname voor de Surinamers" weerklinken, en wanneer dan Suriname een bevolking zal hebben van een ander ras en een andere mentaliteit, niet door stamgevoel met de moederlandsche verbonden, dan zal Suriname zelfs niet als „dominion” tot het Nederlandsche Rijk blijven behooren. Dat is wel wat ver gezocht en een ander verschiet, zoowel met betrekking tot het Oosten als tot het Westen is ook nog wel denkbaar. Ik heb hier tegenover gesteld dat, naar de geschiedenis leert, juist van een stamverwante koloniale bevolking allereerst een afscheidings-beweging te verwachten valt, natuurlijk wanneer de toestanden in de kolonie er rijp voor zijn, en dacht daarbij begrijpelijkerwijze aan de Vereenigde Staten; ook in de voormalige Spaansche en Portugeesche koloniën echter waren het in de eerste plaats de met het moederland meest stamverwante hoogere en middenklasse van wie de zelfstandigheids-beweging uitging. En zelfs de neger-republiek Haïti zou kunnen gelden als een voorbeeld van dezelfde strekking, voor zoover aanvankelijk de gedachte aan een zelfstandig gemeenebest alleen onder den hoogeren stand der creolen kan hebben geleefd; de vrije mulatten verlangden 
slechts burgerrechten en de slaven persoonlijke vrijheid. Waar dan natuurlijk tegenover staan Canada en Australië als voorbeelden dat een stamverwante overzeesche bevolking ook in eenzelfde staatsverband met het moederland kan willen blijven voortleven, wanneer dit laatste een verstandige politiek voert.

Tegenover de vrees van Dr. L. dat met een bevolking van ander ras en andere mentaliteit Suriname voor Nederland verloren zou gaan heb ik willen stellen de tot nu toe steeds gebleken loyaliteit van den Amerikaanschen neger, die zoowel in de Zuidelijke Staten der Unie als op de Westindische eilanden in den loop van eenige eeuwen zoozeer gehecht is geraakt aan den grond welke hem aanvankelijk met geweld als nieuwe verblijfplaats werd opgedrongen en die zoo trotsch is op zijn tegenwoordige nationaliteit; de Amerikaansche negers vochten mede in den grooten Europeeschen oorlog en de Britsche koloniën leverden hun „West Indian contingent”. Haiti is het eenige voorbeeld van een negerrepubliek buiten Afrika en deze republiek ontstond onder den invloed eener crisis in het moederland en niet minder onder dien der oneenigheden tusschen de vrije kolonisten onderling. Intusschen onderwierpen zoowel Haïti als de mulatten-republiek St. Domingo zich na honderd jaar van onafhankelijkheid zonder daadwerkelijk verzet aan een Amerikaansch protectoraat.

$\mathrm{Nu}$ wijst Dr. L. wel op de Surinaamsche boschnegers, die, behalve wat de taal betreft, echte Afrikanen zijn gebleven, en op de afgoderij in de binnenlanden van Haïti waarover verschillende oudere auteurs hebben geschreven. Het element der boschnegers in Suriname vormt een anachronisme, dat Nederland niet tot eer strekt (in de Br. West Indiën bestaat dit element allang niet meer) en met den voodoe-dienst op Haït zullen de Amerikanen wel weten af te rekenen; met het gevaar evenwel voor afvalligheid heeft een en ander niet te maken.

In Javanen als kolonisten voor Suriname zag Dr. Lens een gevaar omdat deze, behalve hun mentaliteit en hun bijgeloof, ook hun hadjis en hun vrouwen medebrengen; 
bij dat woord vrouwen plaatste ik een uitroepteeken. De hadjis kunnen de Javanen wel thuislaten, maar de vrouwen moeten meekomen; aan een kolonisatie van enkel of hoofdzakelijk mannen zou men niet veel hebben. De onder de Aziaten in Suriname nogal eens voorkomende „crimes passionels" worden in het land zelf, behalve aan de Oostersche opvattingen omtrent huwelijkstrouw, ook nog toegeschreven aan een relatief gebrek aan vrouwen; zoowel bij de Britsch Indiërs als bij de Javanen in Suriname zijn de vrouwen nog steeds numeriek in de minderheid. Het vraagstuk der venerische ziekten (ik had Dr. Lampe wel degelijk gelezen) is er dunkt mij een op zich zelf.

Wanneer ik den indruk zou hebben gekregen als zou ook Dr. Lens van de tegenwoordige Surinaamsche bevolking - uit meer dan een half dozijn verschillende rassen samengesteld - niet de geschiktheid verwachten om, onder betere - vooral hygiënisch betere - voorwaarden levende dan thans, zich te vermenigvuldigen en tot welvaart te geraken, dan kon dat mede een gevolg zijn van het aantreffen, in het eerste pleidooi van den geachten schrijver, der afgezaagde aardigheid, zij het dan ook tusschen aanhalingsteekens geciteerd, aangaande de groote inundatie welke het mogelijk zou maken om met een geheel nieuwe bevolking te beginnen; die mogelijkheid is er nu eenmaal niet en, heb ik Dr. Lampe goed gelezen, dan wil ook deze laatste de bestaande bevolking in hygiënisch betere conditie brengen.

Dr. Lens ziet bij doorvoering van zijn plan een ,naturellen-vraagstuk" in het verschiet, of liever hij acht dat vraagstuk onmiddellijk aanwezig zoodra een Hollandsche kolonisatie in Suriname zou aanvangen, en heeft willen aanbevelen dit vraagstuk op te lossen, om derwille van de hygiëne, door een systeem van afscheiding als Generaal Herzog voor Zuid-Afrika voorstaat. Maar, het Zuidafrikaansche naturellen-vraagstuk is bij lange na niet in de eerste plaats een hygiënisch vraagstuk en wie in Suriname alzoo tot de naturellen zouden moeten worden gerekend is niet duidelijk; ook de ruim $40 \%$ der tegenwoordige bevolking, thans in de statistiek begrepen onder de 
algemeene benaming van ,inboorlingen”? Deze rubriek omvat hoofdzakelijk alle Surinaamsche kleurlingen, van de meest uiteenloopende schakeering.

Een scheidsmuur, doch geen waterdicht schot, om der wille van de hygiëne en vermoedelijk toch weer niet uitsluitend een hygiënische scheidsmuur, dat opent eigenaardige perspectieven. Dat thans de boschneger gelijkberechtigd is met den beschaafden kolonist, zelfs met den Hollandschen ambtenaar, daarover kan men verschillend denken; de boschneger in zijn isolement trekt van die ge lijkheid niet veel profijt. Maar een differentiatie welke aan den ontwikkelden kleurling een anderen status zou toekennen dan aan den Hollandschen boerenarbeiderimmigrant ware toch niet minder bedenkelijk.

Ik geloof dat Dr. Lens zich liever had moeten bepalen tot zijn oorspronkelijke verwijzing naar de groote moeilijkheid om Hollandsche immigranten van stonde afaan vrij te houden van de ziekten waarmede het bewoonde gedeelte van Suriname nu eenmaal is geinfecteerd. Dat is dan echter een argument tegen het plan om zonder talmen, dus terwijl het assaineeringswerk nog in het tegenwoordige stadium verkeert, een aanvang te maken met Europeesche immigratie.

Nogmaals, dit alles zijn bijkomstigheden! Heeft Nederland het menschen-materiaal voor een kolonisatie als de door Dr. Lens bepleitte en zouden inderdaad de belangen van Nederland en van Suriname - wanneer men die werkelijk los van elkander mag noemen in dit verband er door gediend worden?

De gep. Kolonel der Artillerie F. H. Umbgrove wijst in het Koloniaal Weekblad op de bezwaren tegen het planLens welke gelegen zijn in de mentaliteit van ons volk en in den economischen toestand der arbeiders in Nederland van den tegenwoordigen tijd.

Men informeere maar eens ter bevoegder plaatse wat er tijdens den oorlog terecht is gekomen van de pogingen om de tijdelijk werkelooze havenarbeiders aan werk te zetten van eenigzins anderen aard dan zij gewoon waren te 
verrichten en in een eenigzins andere omgeving, hoewel nog altijd dicht in de buurt. Men denke maar eens aan den loonstandaard in Holland van den tegenwoordigen tijd, aan de steunverleening aan werkeloozen en aan de uitkeeringen welke men zich heeft gedacht voor ontginningswerk in Drente.

De trekboeren in Zuid-Afrika en de Amerikaansche pioniers die met de „,covered wagon" Westwaartsch trokken waren figuren uit de vorige eeuw en volgers der tradities, van ettelijke geslachten vóór hen, eener kolonisatie welke was aangevangen in een heel anderen tijd dan de onze. Blanke kolonisten in Suriname zouden bovendien voor heel andere moeilijkheden komen te staan dan zij. Dr. Hendrik P. N. Muller, in wiens gezelschap ik in 1902 de Hollandsche boeren buiten Paramaribo bezocht, achtte het bestaan dezer menschen voor zijn Afrikaanders niet aantrekkelijk genoeg.

Suriname is een tropisch land, dat tropische landbouwproducten moet voortbrengen, in concurrentie met andere tropische landen, en de loonstandaard speelt daarbij een zeer groote rol; men lost deze moeilijkheid niet op door te spreken over de grootere prestaties van Europeesche arbeiders en machinaal bedrijf. Ook in het verslag der commissie die een onderzoek heeft ingesteld naar de mogelijkheid eener emigratie van Nederlanders naar Zuid-Afrika wordt gewezen op den lagen loonstandaard van den inheemschen arbeider, waartegen de Europeesche immigrant, als gewoon landarbeider, niet zou kunnen concurreeren.

Het probleem der Nederlandsche landverhuizing is er één, dat van het gebrek aan arbeidskrachten in Suriname een ander! Ook de tegenwoordige Minister van Koloniën is er blijkens een uitlating in de Kamer tegen om het eene met het andere te willen oplossen.

Overbevolking is een betrekkelijk begrip; er zijn in ons land ook menschen die zich ongerust maken over de procentsgewijze afneming van het aantal geboorten en van het geboorten-overschot. Desniettemin bestaat er thans ook in Nederland een landverhuizings-vraagstuk, 
mede omdat onder de vigeerende immigratie-wet in de Vereenigde Staten aldaar slechts een zoo klein aantal Nederlanders voor permanente vestiging wordt toegelaten. En ook al bestond dit beletsel niet, dan zou toch blijven bestaan het nadeel dat Nederlandsche emigratie, wanneer die zich richt op landen onder vreemde vlag, daadwerkelijk beteekent verlies voor den Nederlandschen stam; dat valt niet te verhelpen.

Reden te meer om alle krachten in te spannen tot de verdere ontwikkeling van tropisch Nederland, want daar alleen ligt ons expansie-gebied, zij het dan ook niet voor landbouwarbeiders. Meer Hollanders in Oost-Indië wijlen de groot-Nederlander Cremer wees er reeds jaren geleden op - beteekent meer ruimte in het Moederland, ook al keeren de meesten naar Holland terug en ook al is er in de tropen slechts behoefte aan intellectueelen en geschoolden. Tegenover hen die terugkomen, en voor een groot deel op de arbeidsmarkt niet meer meetellen, komen anderen aan de beurt ,to do their bit" daarginds en tegenover de toenemende geschiktheid van inlanders in bepaalde gebiedsdeelen voor verschillende posities welke daar vroeger door Europeanen moesten worden bekleed staat het ontsluiten van telkens nieuwe sfeeren met primitievere toestanden en verhoudingen.

Suriname te betrekken in dit proces is thans aan de orde en ook daar moet begonnen worden met het begin. Om het land tot ontwikkeling te brengen is allereerst noodig een versterking van het voor tropischen landbouw geschikte arbeiders-contingent en dat kan practisch slechts geschieden door overbrenging van inlandsche werkkrachten uit Java; er is geen andere keuze!

En dat is niet een middel dat altijd nog beproefd kan worden; zoolang de poenale sanctie nog bestaat - en de animo aanwezig is - moet gebruik worden gemaakt van de gelegenheid om in Suriname het Nederlandsch-indische contingent te versterken. Tegelijk daarmede moeten krachtige en doeltreffende maatregelen worden genomen om den gezondheidstoestand aldaar te verbeteren, ten einde uit de 135000 menschen die er reeds wonen en de 
emigranten die er alsnog heen zullen kunnen worden gevoerd een goede kern te verkrijgen voor een toekomstige, meer aan de grootte van het land en de belangrijkheid zijner hulpbronnen geëvenredigde bevolking.

Een prooi voor kapitalistische uitbuiting zal Suriname door een versterkte immigratie van Javanen niet behoeven te worden; er zijn allerlei factoren die dat kunnen beletten, niet het minst de mogelijkheden welke openstaan voor den kleinen en middenstands-landbouw.

Ook zal het emigratie-gebied van ons volk er niet door teloor gaan, integendeel, ons natuurlijk expansie-gebied zal er door worden vergroot.

Zelfs laat zich in de toekomst Suriname denken als een land waar Hollandsche boom- en vruchtenkweekers zich als kleine plantagehouders zullen kunnen vestigen, zooals de continentale Amerikanen die zich op Pto Rico als „fruitfarmers” hebben neergezet, maar zoover zijn we thans nog niet. Voor het oogenblik gaat het er om de zoo moeilijk op te wekken belangstelling voor Suriname in goede banen te houden en ik zie een gevaar in het propageeren van het denkbeeld als zou Suriname door den handen-arbeid van Hollanders moeten worden ontgonnen en in cultuur gebracht.

\section{LITERATUUR}

Encyclopediae van Ned. W. I.

Koloniale Verslagen.

JoHn F. Fraser, Panama and what it means. 1913.

VAUGHan CoRnish, The Panamic Canal and its makers 1909.

LindSAy Marshall, The Story of the Panama Canal 1913.

I. A. Wright, Cuba.

Harry E. Montgomery, Vital American problems 1908.

Diverse handboeken v. d. V. S. etc.

Noordwijk a/Zee, Juli/Aug. 1927. 